\title{
Estimation of Medication Dispensing Errors (MDEs) as Tracked by Passive RFID-Based Solution
}

\author{
Anas Mouattah, Institute of Maintenance and Industrial Safety, University of Oran 2 Mohamed Ben Ahmed, Algeria \\ Khalid Hachemi, Institute of Maintenance and Industrial Safety, University of Oran 2 Mohamed Ben Ahmed, Algeria \\ (iD https://orcid.org/0000-0002-8358-3584
}

\begin{abstract}
Errors from dispensing medicines, as part of medication errors, can have deadly consequences. Notwithstanding the occasional incidental reports, the impact of such errors remains significant given the high amount of medicines distributed daily. Here, the authors case studied the medication dispensing errors and the resulting impact on patient safety vis-à-vis a medico-surgical emergency department of a local university hospital center. The approach comprises two parts: first, an estimation of medication dispensing error rates; and second, a suggested passive radio frequency identification based solution aimed to reduce such incidents. The benefits of the adapted novel solution relative to the commonly used systems will be highlighted. They conclude with an overview of the study results and provides insights on how attending to this key challenge of medication dispensing errors will further enhance future health informatics practices and research.
\end{abstract}

\section{KEYWORDS}

Dispensing Conformity, Error Detection, Hospital Management Systems, Medicines Dispensing Errors, Passive RFID, Patient Safety, Radiofrequency Identification, Similarity

\section{INTRODUCTION}

Patient safety standard is generally gauged via medication errors, whether in the form of commission and/or omission. As such, no matter the extent, enhancing patient safety is paramount and has always been the focus of professionally responsible healthcare providers. To date, a variety of technologies as well as strategies, including hospital information system (HIS), barcode technology and pharmacy management systems like automated dispensing cabinets (ADCs) supported with e-recordings have been explored in healthcare facilities to improve key measures of patient safety, specifically, reducing the medication dispensing errors (MDEs). Today, a clever way to strictly enforce and uphold patient safety and security in healthcare facilities such as hospitals, pharmacies, multi-provider clinics and wellness care centers is via a mandate to significantly decrease medication and other clinical treatment errors.

\section{DOI: 10.4018/IJHISI.20210701.0a6}

This article, published as an Open Access article on December 11, 2020 in the gold Open Access journal, International Journal of Healthcare Information Systems and Informatics (IJHISI) (converted to gold Open Access January 1, 2021), is distributed under the terms of the Creative Commons Attribution License (http://creativecommons.org/licenses/by/4.0/) which permits unrestricted use, distribution, and production in any medium, provided the author of the original work and original publication source are properly credited. 
Our study to address patient safety in MDEs is chiefly motivated by the need to achieve two primary goals. First, we are interested to perform basic evaluation of patient safety within the context of a medico-surgical emergency department (MSED) as part of a local university hospital center (UHC) environment, as unfortunately, despite the UHC being equipped with a HIS to support both e-prescription and patient's e-data recording, there is no system available nor implemented to do conformity check in dispensing medicines; consequently, no information about dispensing error ratio has been made available to ensure patient safety. The suggested evaluation approach adopts the PazourMeller (2012) mathematical model in which patient safety may be assessed via specific processes relating to the estimation of MDE rates. Second, to more fully address the patient safety issue and to keep material traces on medication practices at UHC, we attempt to simulate the performance of an adapted passive RFID-based configuration to fit the MSED. While the detection of medication errors is the general goal, it is critical that such errors, which might lead to fatal consequences, should not be discovered late; for this purpose, our study suggests a configuration that involves having passive RFID readers installed at the UHC patient's bedside so as to monitor the medication stage of the overlap between dispensing and administration of medicines. This has the aim of limiting maximally the possibility of medication error, while simultaneously improving the cost-effectiveness, userfriendliness and the integrability of existing systems.

The rest of this paper is organized as follows. In Section 2, a background discussion of the general rationale underlying our research is overviewed. Next, in Section 3, the adopted method of estimating the MDEs is explained along with the proposed passive RFID-based solution. In Section 4, the MDEs study results are unveiled. A detailed analysis of the findings and the feasibility of the proposed solution follow in Section 5. Finally, Section 6 summarizes the findings and provides insights on how attending to the research challenge noted in our study will further enhance future health informatics practices and research.

\section{BACKGROUND}

MDE is defined as a mismatch of the medication actually taken by the patient vis-à-vis those given in the documented prescription, an incident of MDE can often happen in multiple ways, including, but not limited to, a wrong medicine being delivered, an incorrect concentration and/or dosage of the medicine is being prepared, or even having the right medication, but sending it to the wrong location, the wrong patient and/or at the wrong timing. Unfortunately, most if not all of these preventable MDEs can have serious consequences, which may lead, in some cases, to permanent disability or even death. Indeed, it is estimated that over 250,000 people die yearly due to medication errors in the US (Anderson \& Abrahamson, 2017; Ker et al, 2010).

Similarly, Hartnell et al. (2014) claimed that such medication errors can engender annual losses of over 7 billion $€$ in term of medication wastage. In the absence of a reliable decisive tool, the causes of dispensing errors, made by pharmacists or via a dispenser, can only be traced by self-evaluation techniques, for example, the deployment of a well-designed survey or questionnaire. Importantly, different researchers have alluded to various qualitative factors linked chiefly to these causes, for example, being under-staffed or time pressed, overload command, work fatigue, physical and/or mental obstruction during medication dispensing and "look-alike/sound-alike" medication issues (Anacleto et al., 2005; Edoh et al, 2016; Berdotet al., 2019; Seidling \& Bates, 2019; Caleres et al., 2020).

\subsection{Past Solutions}

Before adopting technologies in pharmaceutical services, hospitals used to rely on nurses and caregivers to distribute medicines, which has only increased the potential for MDEs. Soon, more reliable approaches were explored, including the use of HIS to save time for the caregivers while reducing medication errors. Indeed, when HIS first appeared in the 1960s, it was used solely for administrative purposes; eventually, it was cleverly exploited for logging in of timely health history 
data of hospitalized patients and the continuous tracking of their medication use in order to improve safe clinical practices in complex, evolving healthcare environments (Ball, 1971; Barnett, 1974; Collen \& Miller, 2015).

In 1995, the barcode technology was introduced for use in hospitals and it soon became mandatory in 2004 in US hospitals. Nowadays, the adoption of barcode alongside with the HIS is widespread as it matured into a convenient care delivery process vis-à-vis the different aspects and management tasks in healthcare facilities, including the timely identification, compliance verification and backtrack tracing of medicines being dispensed to specific patients. This significantly improved patient safety and reduced administrative errors by about eight-two (82) percent (Oren et al., 2003; Cummings et al., 2005; Poon et al., 2006; Voshall et al., 2013; Muroi et al., 2017).

More recent solutions such as the automated dispensing cabinets (ADCs) supported with e-recording capabilities have also become widely deployed to secure medication storage and to decentralize over care units. ADCs can help proactively in monitoring drug usage patterns, thereby controlling its appropriate dissemination and use (Balka, et al. 2007; Lin \& Hsieh, 2017; Lee \& Chen 2019).

\subsection{RFID-Based Solution}

In the last decade, the radio-frequency identification (RFID) technology emerged, making its way through the healthcare sector while incentivizing smarter and handier solutions. When RFID was first introduced in 2005 to healthcare institutions as a real-time locating system (RTLS) with the ability to simulates the role of barcode without requiring a physical contact, its usage, over the years, have penetrated many healthcare routines, including managing the hospital assets and staff (Wamba et al 2013; Camacho-Cogollo et al 2020).

Wu et al. (2005), Ngai et al. (2009) and Yao et al. (2010) provide other examples of RFID uses. These include RFID integrated into the HIS to manage medication use, allowing the use of RFID tags to automatically identify the patient's identity, compare the medications a patient is taking with the given prescription, and then synchronizing the record in the patient's medical record.

\section{MATERIALS AND METHODS}

Here, the Pazour-Meller (2012) mathematical model, an approach researchers have used to address the issue on MDEs for ADCs, is now extended to gather empirical data for satisfying the first key goal of the present study. Additionally, the proposed passive RFID-based solution, which will be used to achieve the second key goal of our research, is discussed next.

\subsection{Estimating MDEs}

In order to imitate MDE occurrence possibility, the similarity rating for each pair of medicines is expressed based on their common medication categorical factors.

The list of medicines [see Appendix], which represents the research material of the present study, contains eighty-two (82) medicines used in the MSED of the UHC. In this case, the factors of similarity rating involve: medicines therapeutic class, dosage forms, demand frequency, concentration, and sound-alike/look-alike medicines names. The following steps of the method are then performed.

First, the value of similarity rating is assigned within the interval $[0,1]$, where 0 represents the strict dissimilarity of medicines pair, which refers to the lowest occurrence possibility of dispensing error, while 1 represents the absolute similarity, which matches the highest error occurrence possibility.

Second, the result of medication similarity rating is a function of the number of factors in common relative to the maximum number of factors that can occur. Expressing this mathematically, we denote $S_{i j}$, $l$ and $L$ to refer respectively to the similarity rating of the medicines $i$ and $j$, the number of common factors and the maximum number of factors, which means $1<\mathrm{L}$ : 
Figure 1. High-level flowchart of the similarity check approach
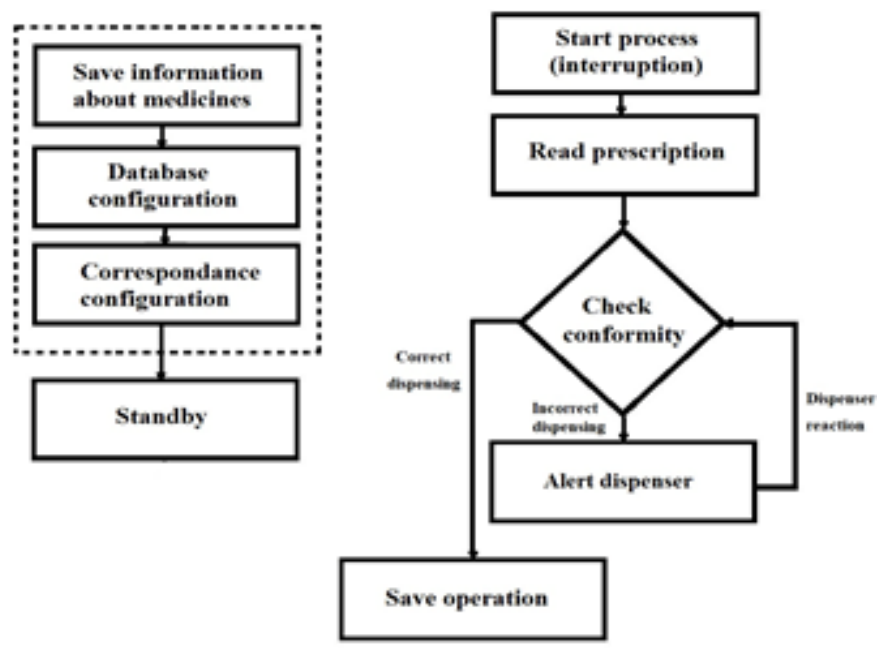

$\mathrm{S}=\frac{l}{L}$

For our case, $\mathrm{L}=5$.

Third, the similarity rating $\mathrm{S}_{\mathrm{ij}}$ is related, by definition, directly to the possibility of dispensing error occurrence between the pair of medicines $i$ and $j$. Thus, the risk of dispensing error $R$ can be defined relatively to $\mathrm{S}$ as follows:

$R=\mathrm{S}^{\mathrm{k}}$ with $(\mathrm{k}=1,2,3 \ldots)$

where the value of the scaling parameter $\mathrm{k}$ is chosen according to the patient safety priority to the hospital; note that as $\mathrm{k}$ approaches 1 when the hospital administration takes in consideration the primacy of patient safety and vice versa.

Figure 1 represents the algorithm to get the similarity ratings of medicines list in MSED of the UHC [appensix 1]. DEV C++ IDE (Version 2) was used to code and run the algorithm.

Fourth, as the algorithm is about comparing the medicines in the list, and in order to simplify its execution, the list is coded into numerals. This involves names of the medicines, therapeutic classes, dosage forms and demand frequencies, which are all linked to a reference number.

Finally, in order to consider the different measurement units of concentration, this categorical factor is denoted using 5-bits coding, where the first bit on the left refer to the unit and the rest to the value. The demand frequencies of the medicines are obtained by interrogating the pharmacist of the UHC. The specifications are illustrated in the Appendix.

Overall, the list is declared as a two-dimension array, where medicines with the same factors in common have the same references in common.

\subsection{Passive RFID-Based Solution}

Radio-identification, more commonly, radiofrequency identification (RFID) is a means to collect and disseminate information via radio waves. It comprises four parts: (a) the tag, which is attached to objects or humans to store the information associated with them and composed mainly of an 
Figure 2. The proposed RFID based configuration
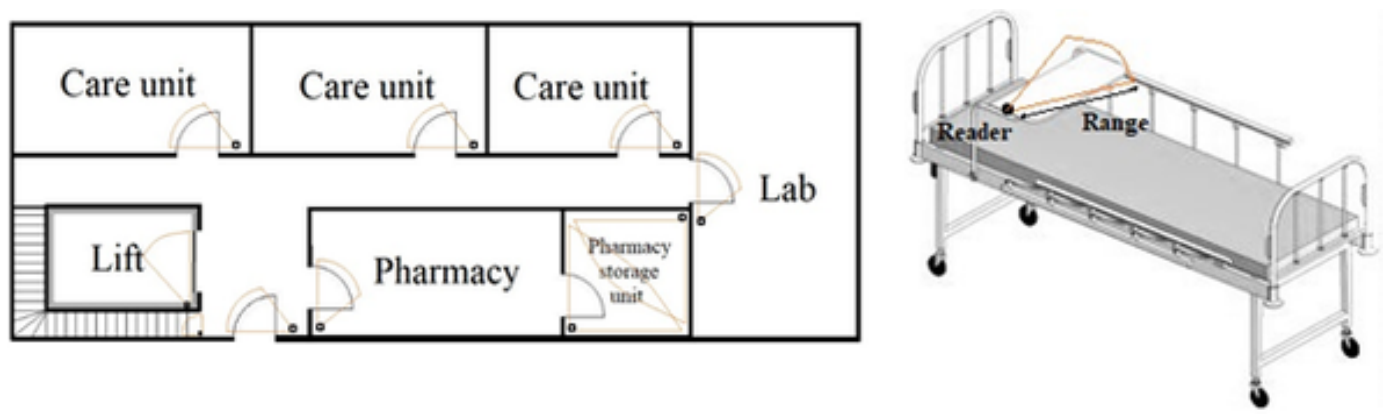

integrated circuit and an antenna, is where data are stored; (b) the reader that communicates with the tag via an antenna to read it or write on it; (c) the database, which is responsible for storing and evaluating the tag's information; and (d) the backend, which is where the data retrieved are exploited in a planned action.

RFID readers can be in the shape of a fixed design or designed as portables, based on usage needs. Fixed readers have two phases of optimal emplacement: the first phase is used when expecting moving objects such as human indoor traceability, where the readers are placed usually in portals, whereas the second phase is meant for static objects, where the readers cover all the area. This latter phase is generally used in storage spaces.

The proposed novel solution, which is dedicated for the MSED at the UHC, entails both fixed and mobile RFID readers. Moreover, to ensure its feasibility, some quality standards are being set with the aid of healthcare experts from the hospital:

- Patient safety improvement: the solution should improve the traceability of dispensing medicines and also the patients.

- Ease of adoption: the solution should be easy to implement, simple to learn and operate, and convenient to apply.

- Cost effectiveness: the solution should be functional with the deployment of a reasonable amount of equipment, that is, an optimal number of readers - minimum readers that cover the maximum working area -without affecting the main system mission, that is, the traceability.

- Reliability with independency: the solution should be used in parallel with the existing procedure to maximize the reliability, in order to avoid new or unconsidered types of errors that might come when adopting new technologies (Berger \& Kichak, 2004; Koppel et al., 2005; Lee, 2015).

\subsubsection{Hardware Implementation}

The MSED has three floors, each floor having a number of care units. Patients are treated in the same unit if they fall within the same therapeutically class. Each unit has a capacity of twelve (12) patients (twelve moving beds). Each bed has a reference of emplacement where medical equipment is power-supplied and connected to the HIS. All three levels are almost identical. The pharmacy of the MSED is located on the first floor (Figure 2).

In the proposed solution, an RFID tag is attached to each medicine, medium range readers are implemented to cover each portal of the MSED including the lift and the entrance and another low range reader is fixed on each patient bed. In addition to the reader implanted in the portal of the pharmacy and its storage unit, three medium range readers are added to cover all the area of the storage unit of the pharmacy. 


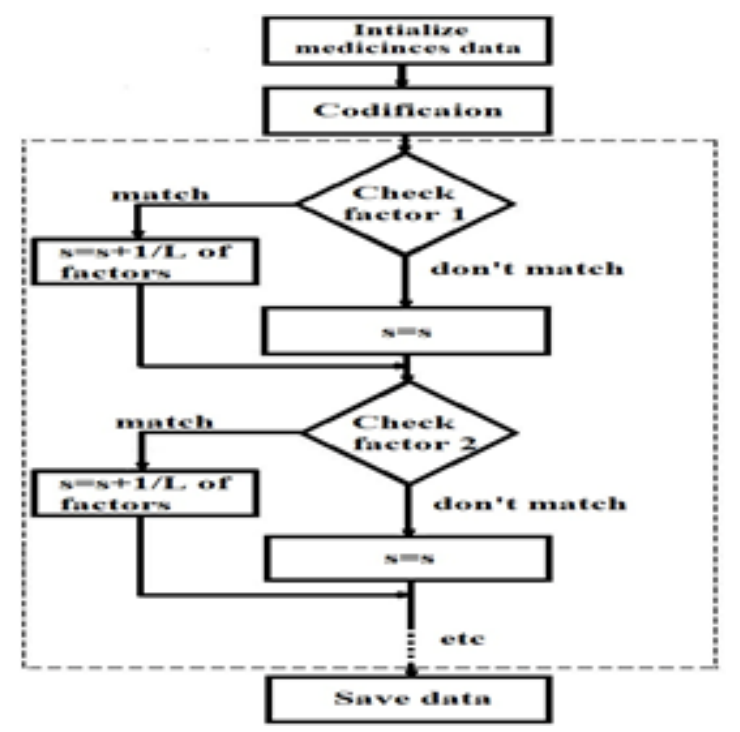

\subsubsection{Software}

The alert triggering and data saving are handled via software. Figure 3 shows the flowchart of the proposed solution.

First, the database should be initialized (each medicine and its associated tag would be identified in the database). After tagging each bottle of medicines, and by linking it to the HIS, the result of dispensing conformity check is indicated by a light signal.

An interruption occurs when the reader on the bed reads a tag corresponding to a medicine. At that moment, the program checks the prescription for any kind of dispensing error to ensure that the right medicines have been distributed to the right patient with the right dose and form, at the right time. The non-conformity of any of the previous five "rights" will then generate an alert in form of a red light.

The next section highlights the results of the estimation of the MDEs in the MSED of the local UHC.

\section{RESULTS}

The pharmacy of the MSED contains sixty-seven (67) different medicines, and some among them also have different concentrations. Hence, the list is extended to eighty-two (82) items.

Each item is checked compared to the others with no repetition or self-check, yielding a total number of pairs of 3,321 pairs as given in formulae (3) and (4) below:

Number of pairs $=$

$\frac{(\text { number of medicines }) X(\text { number of medicines }+1)}{2}-$ number of medicines 
Table 1. Similarity matrix summarized

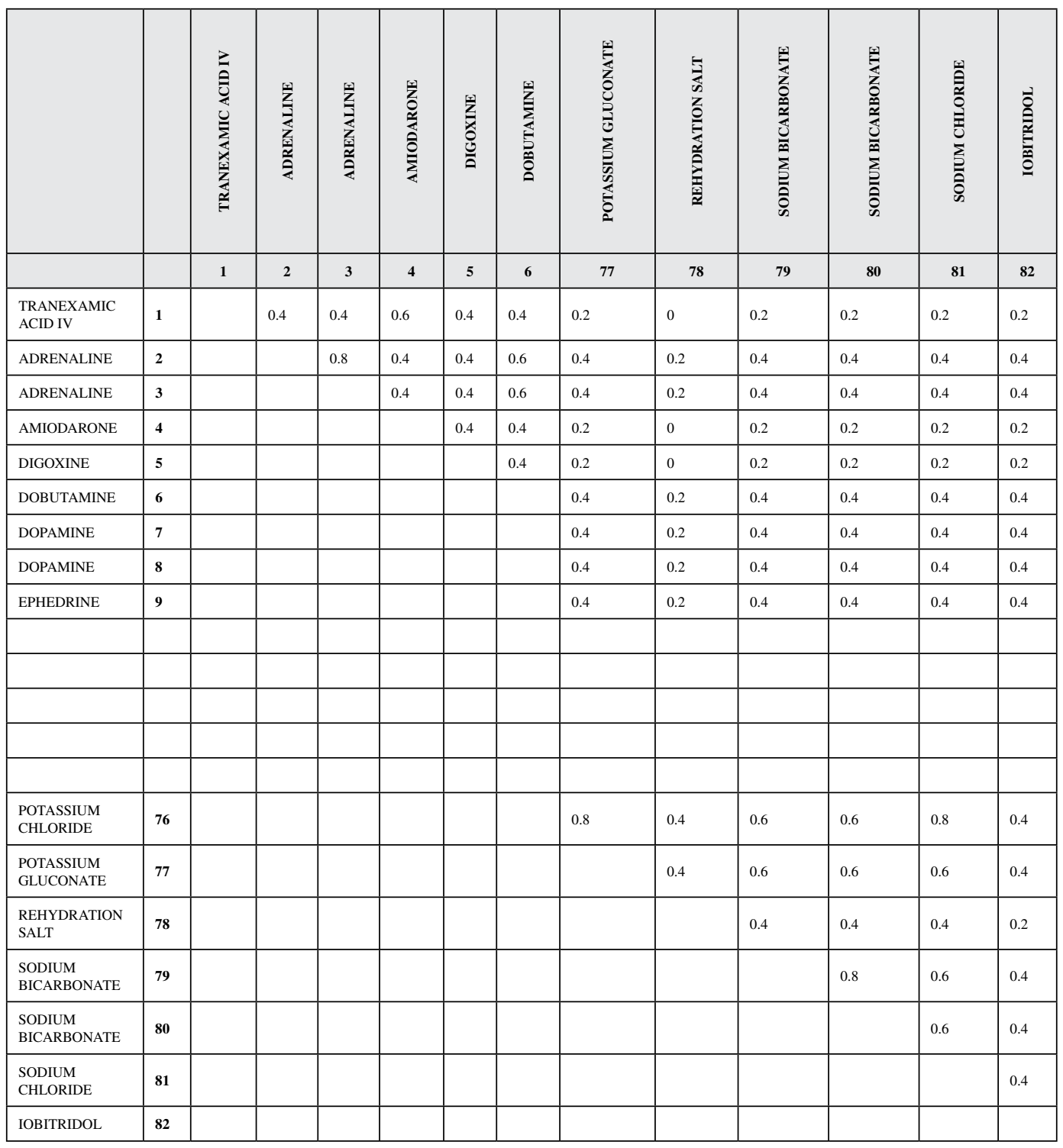

Number of pairs $=$

$\frac{82 \times 83}{2}-82=3,321$ pairs

As shown in Table 1, the result of similarity check is a symmetric matrix where $S_{\mathrm{ij}}=\mathrm{S}_{\mathrm{ji}}$.

The bar graph shown in Figure 4 corresponds to the number of medicine pairs per rating $S$, which is obtained by referring to the similarity matrix. Depending on the definition set above, similar medicines are those with $S=1$; thus, $5.81 \%$ of the medicines in the list are nearly similar (193/3321 pairs above average, as their similarity rating are superior to 0.5 ). 
Figure 4. The number of medicine pairs per similarity rating

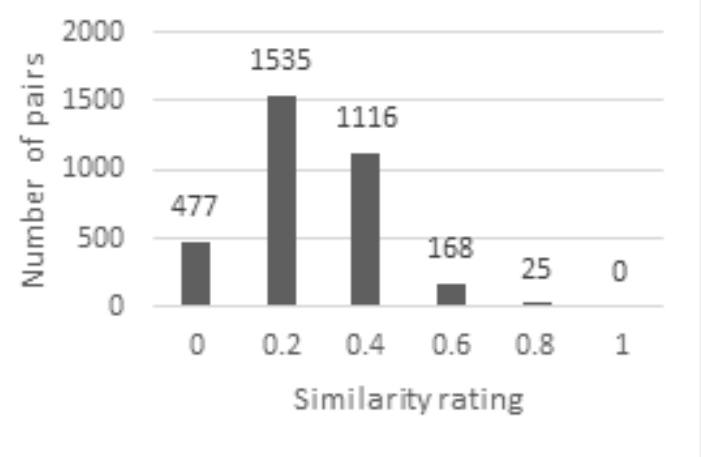

For different values of the scaling parameter K, results shown in the graph in Figure 5 unveil the dispensing error risk relative to the number of pairs of each similarity rating.

In our case study, $\mathrm{K}=3$ is considered based on number of staff and interns, as it is a major factor of error dispensing, and since, by definition of the model, the choice of $\mathrm{K}$ is estimative. We have $\mathrm{R}$ rises alongside $\mathrm{S}$ attending $21.6 \%$ for medicines with similarity equals to 0.6 and scaling parameter of 3 , and rises to $51.2 \%$ for $\mathrm{S}=0.8$ and $\mathrm{K}=3$.

Note that $\mathrm{R}$ is defined as the probability of committing an error while dispensing and not the error rates after dispensing. Briefly, 51.2\% represents the risk of dispensing error occurrence and not the percentage of medicines wrongly dispensed.

In our case, high similarity rates are mainly related to the same medicine with different concentrations, such as Dopamine $50 \mathrm{mg}$ and $200 \mathrm{mg}$.

Moreover, the study results show ratios that seem relatively high; yet, they remain acceptable in accordance with previous studies (Anacleto et al, 2005; Cheung et al., 2009; Berdot et al., 2019). As in all studies when error ratios are high, for example, where the dispensing errors attain a rate of up to four-five percent (45\%), the researchers would typically annotate the process and double-check the conformity between prescriptions and the dispensed medicines (Anacleto et al, 2005; Cheung et al., 2009; Berdot et al., 2019; Seidling et al., 2019; Caleres et al, 2020).

Figure 5. The dispensing error risk related to $S$, for different values of $K$

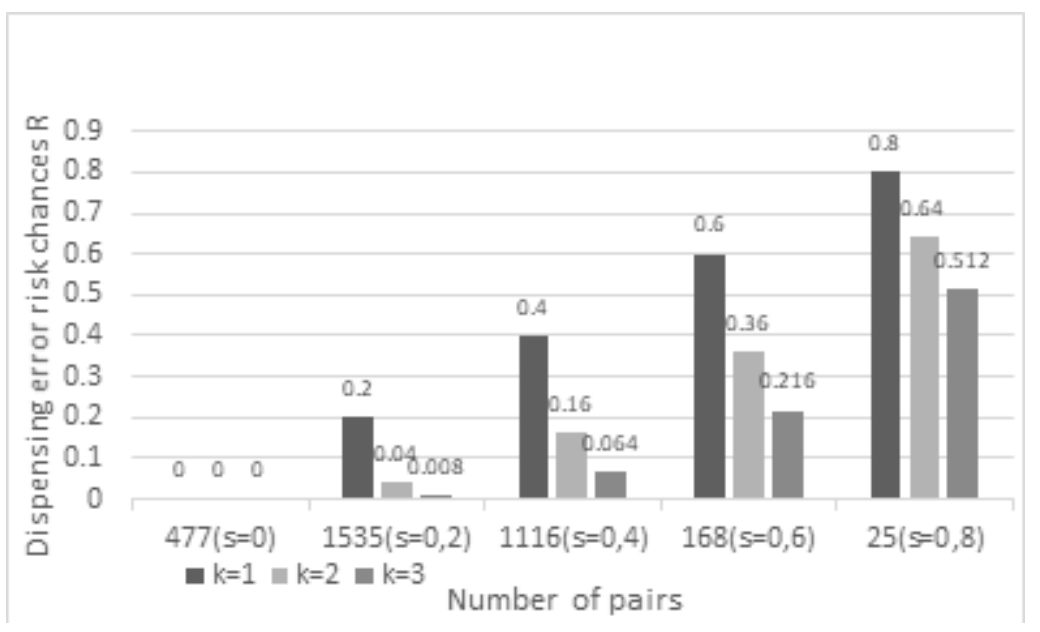


In order to limit the MDEs, an intervention is required. A passive RFID-based solution is proposed, allowing the process to promote a safer drug distribution by triggering an alert, in case of an error, and also to maintain a synchronized data record to be exploited for improving patient safety. Details regarding the adoption of this solution and its added value are discussed in the next section.

\section{DISCUSSION}

We highlight here the study findings and the feasibility of the proposed solution compared with other deployed solutions. Although results of the present case study are based on estimates, in view of the high volume of medicines being dispensed as well as the number of patients being treated daily, these results indicate that the patient safety level at the MSED of the UHC is disturbing, indeed somewhat alarming. The low rates can indicate a big number of errors, depending on the situation. Hence, an intervention is necessary.

The absence of data record about the state of conformity of medication dispensing in the MSED of the UHC poses an obstruction in the way of tracing errors and the need to improve the safety of medication dispense process. We differentiate three sub-stages between dispensing at the pharmacy level to administrating the medicine(s) at the patient's bedside - this is where errors can most easily occur vis-à-vis the sub-stages. For a robust solution that assures a higher level of patient safety, the three sub-stages should be considered in order to restrict maximally the MDEs, or at least, rescind their effect. Hence, it may be argued that the detection of errors just before the administration asserts the dispensing, while the detection before that allows an early intervention, and taking actions on both of these intervening sub-stages can significantly improve the patient safety protocols.

Our novel configuration is devoted to the monitoring of both of the moving objects (readers at portals) as well as the fixed objects (at the pharmacy of MSED). The fixed readers on beds cost about $65 €$ per unit, and, the readers on portals cost $1200 €$ per floor, plus two readers of the storage unit of the pharmacy in the first floor and the RFID tags for medicines with their batches, which means a total price of $12000 €$ to equip the MSED of the UHC. The fixed readers on pharmacy can have an additional role in the inventory management tasks, which improves the operation remarkably in terms of time as well as making it easier to monitor for errors.

As well, in addition to the traceability of the medicines from the moment they leave the storeroom until they reach the target bed, the suggested configuration allows a real time roomprecision traceability for patients. The readers on care units' portals are meant for early detection of non-conformity, while the $2^{\text {nd }}$ check at bed level is considered decisive; it even permits detecting the wrong medicines (concentration, dosage forms and more) being dispensed to patients of the same care unit, along with preventing untimely dispensing as well. Consequently, the adoption of this proposed novel configuration also covers the case of inter-unit transfers of patients.

Beyond this, given that it is easy to distinguish between red and green light, a signal alert to be used for reporting conformity decision will allow patients to be considered, at the administrative level, as an additional means of dispensing monitoring. Since it is about alerting and reporting, the proposed configuration would not interrupt the workflow of the existing UHC information system already in place, including the e-prescription in MSED, which ensures the independency of the proposed approach. Indeed, the adoption of such a technological solution will keep the records of medicines dispensing and traceability in tact both efficiently and effectively, which can be exploited to evaluate and improve the safety of future health informatics practitioners as well as monitoring of patients.

While the barcode management system is used commonly worldwide, it can however be dedicated only for medicines dispensing conformity check. Barcode management systems do not cleverly allow real-time traceability, a key criterion for medical auditing. In addition to its retail scanning limitation, it requires closeness to obverse and read the identities (IDs) of patients and medicines one at a time, as it can read only a single ID at any one time. Ultimately, use of barcodes would seriously lengthen the duration required for the verification process and thus for dispensing medication. Besides, barcodes 
are less secure and not as reliable as RFID systems. This is because barcodes can actually be copied or faked easily; moreover, these codes can also be vulnerable to scratch.

Nonetheless, the choice between adopting mobile RFID readers and our proposed configuration remains somewhat ambiguous. Yet, it should be noted that adopting mobile RFID readers cannot provide objects with 'real-time' traceability and these readers are less ergonomic than the suggested configuration, as they require consciousness when checking dispensing conformity and the staff would take more time getting used to them. Regardless of the limits, the cost is the same as equipping ten beds of the proposed configuration, besides the cost of ensuring availability and maintaining operating batteries in these devices. The same may be said about adopting Active RFID type, not to mention that collision occurs more often when working with high frequencies.

Adopting ADCs can improve patient safety given that it only dispenses the medicines mentioned in the e-prescription, and it remains less fluid, since it is designed for hospitals (not pharmacies) to handle a limited number of demands (about 30 patients per ADC). Also, the dispensing is per prescription only; else, errors might occur at the administrative level. Notably, the time to spend by the staff to become familiar with the technology and the pricing of ADCs (start at approximately $25.000 €$ ) can be exaggeratedly expensive (Moreno et al., 2012). Finally, it is possible for errors to occur at the filling stage. In such a case, the full dependency can be fatal; above all, the traceability is limited only to the medicines stored in the ADCs and not the entire available stock. Consequently, there is no tracking between the pharmacy and the patient (recipient).

In order to assess the efficiency of the proposed configuration, we compare it to the existing solutions, which were placed under test according to three assumed scenarios vis-à-vis the occurrence of three corresponding dispensing errors (like wrong medicine, wrong dose...etc.) at three different sub-stages. As indicated, these scenarios occur chiefly in-between the dispensing and the administration point, which can be used to simulate the detectability of the distribution errors via the adaptation level of different available solutions, including barcode, ADC or RFID-based solutions according to the proposed configuration:

Error 1: Occurs on dispensing, at the pharmacy.

Error 2: Occurs on delivering, i.e. during the path between the pharmacy and a care unit, or between care units.

Error 3: Occurs just before administration inside the care unit, that is, between patients of the same care unit.

Note that stage of Error 3 corresponds to the last checkpoint and it is therefore the most critical, since Error 1 and Error 2 are both rectifiable provided that Error 3 is detected.

Table 2, illustrates the detectability of the errors using the different available solutions, including the proposed configuration.

When adopting the ADC, there is no room for such errors as Error1 - it only opens the drawers containing medicines mentioned in the e-prescription v. the other technologies, where it is not detectable. Error 2 is detectable only via the suggested approach, permitting an early intervention;

Table 2. The adaptation of a deployed solution to the errors compared to the proposed configuration

\begin{tabular}{|l|l|l|l|l|}
\hline \multirow{2}{*}{} & \multicolumn{1}{|c|}{ Barcode } & \multirow{2}{*}{ ADC } & \multicolumn{2}{c|}{ RFID } \\
\cline { 4 - 5 } & & & \multicolumn{1}{c|}{ Mobile Reader } & \multicolumn{1}{c|}{ Proposed Configuration } \\
\hline Error1 & Undetectable & $/$ & Undetectable & Undetectable \\
\hline Error2 & Undetectable & Undetectable & Undetectable & Detectable \\
\hline Error3 & Detectable & Undetectable & Detectable & Detectable \\
\hline
\end{tabular}


conversely, Error3 can also be detected when using barcode and RFID technologies, which makes Error1 and Error2 rectifiable for these technologies, unlike the ADC.

Altogether, the proposed configuration is favored overall as its safety may be considered to be superior to other technologies. Moreover, the barcode usage requires more time per patient, while the mobile reader imposes additional burdens. Put simply, we can say that implementing Passive RFID system has the privilege in our case, compared to common technologies such as the barcode and ADCs. The proposed configuration with the particularity of the additional readers fixed on beds is even more efficient and ergonomic than the Active and mobile RFID systems.

Lastly, the proposed solution meets the quality standards set in conjunction with the hospital head management, given it improves the patient safety by detecting the non-conformity of dispensing medicines while alerting the concerned entity in the case of an error. As well, it is cost effective and it contributes in safe practice without disturbing the workflow of the other in-use systems, which demonstrates the solution feasibility in preventing any unexpected issues that might break down the care system.

\section{CONCLUSION}

In summary, a mathematical approach was adopted to estimate medicines dispensing in the MSED of the UHC. The study results show that $5.87 \%$ of the medicines used are nearly similar; accordingly, the chances of error dispensing might reach $51.2 \%$. For this purpose, a passive RFID-based solution is suggested to prevent these potential errors. The solution is purposely adapted to fit with the MSED at the local UHC.

Compared to other solutions and technologies, our analysis has unveiled the suitability of the proposed system. Moreover, the MDE detection approach presented in this study is based on a multicriteria perspective, allowing proper dispensing to be verified, and simultaneously, the conformity of all medicines' properties during dispensing. A major advantage of adopting our novel configuration is that it provides a continuously updated data record about dispensing medicines, which can be exploited later for evaluation and developmental purposes. Moreover, by installing readers on the patients' beds, the RFID-based solution allows a further conformity checking during a sensitive stage; a stage that corresponds to the end of dispensing and the beginning of administration. Effectively, this would limit maximally the errors occurrence possibility before the patient takes the medicine.

Finally, implementing such a technology necessitates adding another mission; which includes initializing the system, identifying the tags in the database and attaching them to the medicines. Moreover, this mission is periodic, which requires scheduling it in the structure work plan in order to assure the accomplishment of safe medicines dispensing tasks. In order to overcome this limitation, the development of an automated system to handle the generated side missions is suggested, as a future improvement of the proposed solution as well as incentivizing new forms of health informatics practices and research directions.

\section{ACKNOWLEDGMENT}

We thank the staff of the central pharmacy, the MSED of Oran UHC 1er novembre 1954 and Dr. Allaoui M. D for their collaboration and their useful recommendations. This work was supported by the Algerian Ministry of Higher Education and Scientific Research as part of the project "Deployment of RFID technology in hospital logistics chain" under Grant A14N01UN310320180001, directed by Pr. Khalid Hachemi. 


\section{REFERENCES}

Anacleto, T. A., Perini, E., Rosa, M. B., \& César, C. C. (2005). Medication errors and drug-dispensing systems in a hospital pharmacy. Clinics (São Paulo), 60(4), 325-332. doi:10.1590/S1807-59322005000400011 PMID:16138240

Anderson, J. G., \& Abrahamson, K. (2017). Your Health Care May Kill You: Medical Errors. Studies in Health Technology and Informatics, 234, 13-17. PMID:28186008

Balka, E., Kahnamoui, N., \& Nutland, K. (2007). Who is in charge of patient safety? Work practice, work processes and utopian views of automatic drug dispensing systems. International Journal of Medical Informatics, 76, S48-S57. doi:10.1016/j.ijmedinf.2006.05.038 PMID:16997621

Ball, M. J. (1971). An overview of total medical information systems. Methods of Information in Medicine, 10(02), 73-82. doi:10.1055/s-0038-1636032 PMID:5566166

Barnett, G. O. (1974). Massachusetts general hospital computer system. Hospital computer systems. Wiley.

Berdot, S., Blanc, C., Chevalier, D., Bezie, Y., Lê, L. M. M., \& Sabatier, B. (2019). Impact of drug storage systems: A quasi-experimental study with and without an automated-drug dispensing cabinet. International Journal for Quality in Health Care, 31(3), 225-230. doi:10.1093/intqhc/mzy155 PMID:30020459

Berger, R. G., \& Kichak, J. P. (2004). Computerized physician order entry: Helpful or harmful? Journal of the American Medical Informatics Association: JAMIA, 11(2), 100-103. doi:10.1197/jamia.M1411 PMID:14633934

Camacho-Cogollo, J. E., Bonet, I., \& Iadanza, E. (2020). RFID technology in health care. In Clinical Engineering Handbook (pp. 33-41). Academic Press. doi:10.1016/B978-0-12-813467-2.00004-3

Caleres, G., Modig, S., Midlöv, P., Chalmers, J., \& Bondesson, ̊̊. (2020). Medication Discrepancies in Discharge Summaries and Associated Risk Factors for Elderly Patients with Many Drugs. Drugs - Real World Outcomes, 7(1), 53-62. doi:10.1007/s40801-019-00176-5 PMID:31834621

Collen, M. F., \& Miller, R. A. (2015). The early history of hospital information systems for inpatient care in the United States. In The History of Medical Informatics in the United States (pp. 339-383). Springer. doi:10.1007/978-1-4471-6732-7_6

Cummings, J., Ratko, T., \& Matuszewski, K. (2005). Barcoding to enhance patient safety. Agency for Healthcare Research and Quality Case and Commentary. http://www. psqh. com/sepoct05/barcodingrfid1. html

Edoh, T. O., Pawar, P. A., Brügge, B., \& Teege, G. (2016). A multidisciplinary remote healthcare Delivery system to increase health Care access, pathology screening, and Treatment in developing countries: The case of benin. International Journal of Healthcare Information Systems and Informatics, 11(4), 1-31. doi:10.4018/ IJHISI.2016100101

Hartnell, N., MacKinnon, N., Sketris, I., \& Fleming, M. (2012). Identifying, understanding and overcoming barriers to medication error reporting in hospitals: A focus group study. BMJ Quality \& Safety, 21(5), 361-368. doi:10.1136/bmjqs-2011-000299 PMID:22389018

Ker, K., Edwards, P. J., Felix, L. M., Blackhall, K., \& Roberts, I. (2010). Caffeine for the prevention of injuries and errors in shift workers. Cochrane Database of Systematic Reviews, 5. doi:10.1002/14651858.CD008508 PMID:20464765

Koppel, R., Metlay, J. P., Cohen, A., Abaluck, B., Localio, A. R., Kimmel, S. E., \& Strom, B. L. (2005). Role of computerized physician order entry systems in facilitating medication errors. Journal of the American Medical Association, 293(10), 1197-1203. doi:10.1001/jama.293.10.1197 PMID:15755942

Lee, C. Y., \& Chen, Y. P. P. (2019). Machine learning on adverse drug reactions for pharmacovigilance. Drug Discovery Today, 24(7), 1332-1343. doi:10.1016/j.drudis.2019.03.003 PMID:30876845

Lee, J. (2015). Factors Affecting Health Information Technology Expenditure in California Hospitals. International Journal of Healthcare Information Systems and Informatics, 10(2), 1-13. doi:10.4018/IJHISI.2015040101

Lin, C. Y., \& Hsieh, P. J. (2017). Development of an Automatic Dispensing System for Traditional Chinese Herbs. Journal of Healthcare Engineering, 2017, 2017. doi:10.1155/2017/9013508 PMID:29081939 
Moreno, A. M., Nuñez, M. N., Soto, G. R., Coetzee, J. C., Bohorquez, V. M., del Castillo, S. S. F., \& Alonso, A. G. P. et al. (2012). Return on investment for automated dispensing cabinets. European Journal of Hospital Pharmacy. Science and Practice, 19(2), 201-201. doi:10.1136/ejhpharm-2012-000074.304

Muroi, M., Shen, J. J., \& Angosta, A. (2017). Association of medication errors with drug classifications, clinical units, and consequence of errors: Are they related? Applied Nursing Research, 33, 180-185. doi:10.1016/j. apnr.2016.12.002 PMID:28096015

Ngai, E. W., Poon, J. K. L., Suk, F. F. C., \& Ng, C. C. (2009). Design of an RFID-based healthcare management system using an information system design theory. Information Systems Frontiers, 11(4), 405-417. doi:10.1007/ s10796-009-9154-3

Oren, E., Shaffer, E. R., \& Guglielmo, B. J. (2003). Impact of emerging technologies on medication errors and adverse drug events. American Journal of Health-System Pharmacy, 60(14), 1447-1458. doi:10.1093/ ajhp/60.14.1447 PMID:12892029

Pazour, J. A., \& Meller, R. D. (2012). A multiple-drawer medication layout problem in automated dispensing cabinets. Health Care Management Science, 15(4), 339-354. doi:10.1007/s10729-012-9197-8 PMID:22350742

Poon, E. G., Cina, J. L., Churchill, W., Patel, N., Featherstone, E., Rothschild, J. M., Keohane, C. A., Whittemore, A. D., Bates, D. W., \& Gandhi, T. K. (2006). Medication dispensing errors and potential adverse drug events before and after implementing bar code technology in the pharmacy. Annals of Internal Medicine, 145(6), 426-434. doi:10.7326/0003-4819-145-6-200609190-00006 PMID:16983130

Seidling, H. M., \& Bates, D. W. (2019). The Pharmacoepidemiology of Medication Errors. Pharmacoepidemiology, 1046-1060.

Voshall, B., Piscotty, R., Lawrence, J., \& Targosz, M. (2013). Barcode medication administration work-arounds: A systematic review and implications for nurse executives. JONA. The Journal of Nursing Administration, 43(10), 530-535. doi:10.1097/NNA.0b013e3182a3e8ad PMID:24061586

Wamba, S. F., Anand, A., \& Carter, L. (2013). A literature review of RFID-enabled healthcare applications and issues. International Journal of Information Management, 33(5), 875-891. doi:10.1016/j.ijinfomgt.2013.07.005

Wu, F., Kuo, F., \& Liu, L. W. (2005, August). The application of RFID on drug safety of inpatient nursing healthcare. In Proceedings of the 7th international conference on Electronic commerce (pp. 85-92). doi:10.1145/1089551.1089571

Yao, W., Chu, C. H., \& Li, Z. (2010, June). The use of RFID in healthcare: Benefits and barriers. In 2010 IEEE International Conference on RFID-Technology and Applications (pp. 128-134). IEEE. 


\section{APPENDIX}

The medicines list in the MSED of local UHC, which represents the research material of the present study, the distinguishing factors are illustrated with details in Table 3.

\section{Table 3. The list of medicines used in this study}

\begin{tabular}{|c|c|c|c|c|}
\hline Therapeutic Class & Medicine Name & Concentration & Dosage Form & Demand Frequency \\
\hline \multirow[t]{15}{*}{ CARDIOLOGY } & TRANEXAMIC ACID IV & $500 \mathrm{mg}$ & Injection & M \\
\hline & ADRENALINE & $0.25 \mathrm{mg}$ & Injection & $\mathrm{H}$ \\
\hline & ADRENALINE & $1 \mathrm{mg}$ & Injection & $\mathrm{H}$ \\
\hline & AMIODARONE & $150 \mathrm{mg}$ & Injection & M \\
\hline & DIGOXINE & $0.5 \mathrm{mg}$ & Injection & $\mathrm{L}$ \\
\hline & DOBUTAMINE & $250 \mathrm{mg}$ & Injection & $\mathrm{H}$ \\
\hline & DOPAMINE & $200 \mathrm{mg}$ & Injection & $\mathrm{H}$ \\
\hline & DOPAMINE & $50 \mathrm{mg}$ & Injection & $\mathrm{H}$ \\
\hline & EPHEDRINE & $3 \%$ & Injection & $\mathrm{H}$ \\
\hline & FUROSEMIDE & $20 \mathrm{mg}$ & Injection & $\mathrm{H}$ \\
\hline & FUROSEMIDE & $250 \mathrm{mg}$ & Injection & $\mathrm{H}$ \\
\hline & ISOPRENALINE & $0.2 \mathrm{mg}$ & Injection & $\mathrm{L}$ \\
\hline & NICARDIPINE & $10 \mathrm{mg}$ & Oral solid & $\mathrm{L}$ \\
\hline & NORADRINALINE & $08 \mathrm{mg}$ & Injection & $\mathrm{H}$ \\
\hline & TRINITRINE & $10 \mathrm{mg}$ & Injection & $\mathrm{H}$ \\
\hline \multirow[t]{9}{*}{ INFECTIOUS } & AMIKACINE & $500 \mathrm{mg}$ & Injection & M \\
\hline & CEFAZOLINE & $1 \mathrm{~g}$ & Injection & $\mathrm{H}$ \\
\hline & CEFOTAXIME & $1 \mathrm{~g}$ & Injection & $\mathrm{H}$ \\
\hline & CIPROFLOXACINE & $200 \mathrm{mg}$ & Injection & $\mathrm{H}$ \\
\hline & GENTAMICINE & $80 \mathrm{mg}$ & Injection & $\mathrm{H}$ \\
\hline & IMIPENEME CISLASTATINE & $500 \mathrm{mg}$ & Injection & M \\
\hline & METRONIDAZOLE & $500 \mathrm{mg}$ & Injection & $\mathrm{H}$ \\
\hline & $\begin{array}{l}\text { SULFAMETHOXAZOLE + } \\
\text { TRIMETHOPRIM }\end{array}$ & $400 / 80 \mathrm{mg}$ & Injection & $\mathrm{L}$ \\
\hline & VANCOMYCINE & $500 \mathrm{mg}$ & Injection & M \\
\hline PSYCHOACTIVE AND & DIAZEPAM & $10 \mathrm{mg}$ & Injection & $\mathrm{H}$ \\
\hline \multirow[t]{2}{*}{ NEUROLEPTICS } & GARDENAL & $40 \mathrm{mg}$ & Injection & $\mathrm{H}$ \\
\hline & NIMODIPINE & $10 \mathrm{mg}$ & Injection & M \\
\hline \multirow[t]{5}{*}{ HEMATOLOGY } & ALBUMINE IV & $100 \mathrm{ml}$ & Injection & $\mathrm{H}$ \\
\hline & ALBUMINE IV & $50 \mathrm{ml}$ & Injection & $\mathrm{H}$ \\
\hline & ETAMSYLATE & $250 \mathrm{mg}$ & Injection & $\mathrm{H}$ \\
\hline & CALCIUM HEPARINATE & $125000 / \mathrm{IU}$ & Injection & M \\
\hline & ENOXAPARIN HEPARIN & $4000 / \mathrm{IU}$ & Injection & $\mathrm{H}$ \\
\hline
\end{tabular}


Table 3. Continued

\begin{tabular}{|c|c|c|c|c|}
\hline Therapeutic Class & Medicine Name & Concentration & Dosage Form & Demand Frequency \\
\hline & ENOXAPARIN HEPARIN & $6000 / \mathrm{IU}$ & Injection & $\mathrm{H}$ \\
\hline & ENOXAPARIN HEPARIN & $8000 / \mathrm{IU}$ & Injection & $\mathrm{H}$ \\
\hline & SODIUM HEPARIN & $25000 \mathrm{IU} / 5 \mathrm{ml}$ & Injection & $\mathrm{H}$ \\
\hline & PHYTOMENADIONE & $10 \mathrm{mg}$ & Oral liquid & M \\
\hline & PHYTOMENADIONE & $10 \mathrm{mg}$ & Injection & M \\
\hline NUTRITION & NUTRISON & $\mathrm{f} / 11$ & Injection & $\mathrm{L}$ \\
\hline \multirow[t]{3}{*}{ PULMONOLOGY } & SOL/INH & $1 \mathrm{Fl} / 100 \mathrm{ml}$ & Other & M \\
\hline & SALBUTAMOL AERO & $250 \mathrm{IU} /$ & Other & $\mathrm{H}$ \\
\hline & SALBUTAMOL NEBUL & $5 \mathrm{mg} / \mathrm{ml}$ & Other & $\mathrm{H}$ \\
\hline \multirow[t]{5}{*}{ INFUSION SOLUTION } & GELATINE FLUIDE MODIFEE & $4 \%$ & Injection & $\mathrm{L}$ \\
\hline & GLUCOSE SOL. & $5 \%$ & Injection & $\mathrm{H}$ \\
\hline & MANNITOL & $/ 10$ & Injection & $\mathrm{L}$ \\
\hline & SODIUM CHLORIDE & $9 \% \mathrm{f} / 250 \mathrm{ml}$ & Injection & $\mathrm{H}$ \\
\hline & SODUIM CHLORURE & $9 \% \mathrm{f} / 500 \mathrm{ml}$ & Injection & $\mathrm{H}$ \\
\hline ANTALGIC & DICLOFENAC SODIUM & $75 \mathrm{mg}$ & Injection & $\mathrm{H}$ \\
\hline \multirow[t]{2}{*}{ ANTI-INFLAMMATORY } & PARACITAMOL ADULT & $10 \mathrm{mg} / \mathrm{ml}$ & Injection & $\mathrm{H}$ \\
\hline & PARACITAMOL CHILD & $2.40 \%$ & Injection & $\mathrm{H}$ \\
\hline \multirow[t]{4}{*}{ DERMATOLOGY } & SOAKED COMPRESS & $20 * 20 \mathrm{~cm}$ & Other & $\mathrm{H}$ \\
\hline & OXYQUINOL SALICYLIC ACID & Bottle/250 & Other & $\mathrm{H}$ \\
\hline & POVIDONE-IODINE & bottle/125 & Other & $\mathrm{L}$ \\
\hline & SILVER SULFADIAZINE & pot $/ 500 \mathrm{~g}$ & Other & $\mathrm{L}$ \\
\hline \multirow[t]{8}{*}{ GASTROLOGY } & PURE ATROPINE & $1 \mathrm{mg} / \mathrm{ml}$ & Injection & M \\
\hline & PARAFFIN OIL & bottle/150ml & ORAL liquid & $\mathrm{H}$ \\
\hline & METOCLOPRAMIDE & $10 \mathrm{mg}$ & Injection & $\mathrm{H}$ \\
\hline & OCTREOTIDE ACETATE & $500 \mathrm{ug} / \mathrm{ml}$ & Injection & M \\
\hline & OCTREOTIDE ACETATE & $100 \mathrm{ug} / \mathrm{ml}$ & Injection & M \\
\hline & OMEPRAZOLE & $40 \mathrm{mg}$ & Injection & $\mathrm{H}$ \\
\hline & OMEPRAZOLE & $40 \mathrm{mg}$ & Oral solid & $\mathrm{H}$ \\
\hline & RANITIDINE & $50 \mathrm{mg}$ & Injection & $\mathrm{H}$ \\
\hline \multirow[t]{5}{*}{ ANESTHESIA } & LIDOCAINE CHLORHYDRATE & $2 \%$ & Injection & M \\
\hline & VISCOUS LIDOCAINE & $02 \mathrm{~g} \%$ & Injection & M \\
\hline & MIDAZOLAME & $5 \mathrm{mg}$ & Injection & M \\
\hline & ROCURONIUM & $10 \mathrm{mg} / \mathrm{ml}$ & Injection & M \\
\hline & VECURONIUM BROMIDE & $10 \mathrm{mg}$ & Injection & M \\
\hline HYPO-ALLERGENIC & PROMETHAZINE & Bottle/200ml & Injection & $\mathrm{L}$ \\
\hline ANTISPASMODIC & PHLOROGLUCINOL & $10 \mathrm{mg}$ & Injection & $\mathrm{H}$ \\
\hline \multirow[t]{2}{*}{ METABOLISM } & CALCIUM CHLORIDE & $10 \%$ & Injection & $\mathrm{H}$ \\
\hline & DEXAMETHASONE & bottle $/ 5 \mathrm{ml}$ & Injection & $\mathrm{H}$ \\
\hline
\end{tabular}


Table 3. Continued

\begin{tabular}{|l|l|l|l|l|}
\hline Therapeutic Class & \multicolumn{1}{|c|}{ Medicine Name } & Concentration & \multicolumn{1}{c|}{ Dosage Form } & \multicolumn{1}{c|}{ Demand Frequency } \\
\hline & HYDROCORTIZONE & $20 \mathrm{mg}$ & Injection & $\mathrm{H}$ \\
\hline & FAST-ACTING HUMAN INSULIN & $100 \mathrm{IU} / \mathrm{ml}$ & Injection & $\mathrm{H}$ \\
\hline & MAGNESIUM SULFATE & $10 \%$ & Injection & $\mathrm{H}$ \\
\hline & METHYLPREDNISOLONE & $40 \mathrm{mg}$ & Injection & $\mathrm{H}$ \\
\hline & POLYSTYRENE SULFONATE & $\mathrm{B} / 454 \mathrm{~g}$ & Oral liquid & $\mathrm{H}$ \\
\hline & POTASSIUM CHLORIDE & $10 \%$ & Injection & $\mathrm{H}$ \\
\hline & POTASSIUM GLUCONATE & 7.46 & Injection & $\mathrm{H}$ \\
\hline & REHYDRATION SALT & $8 \mathrm{~g} / 200 \mathrm{ml}$ & Oral liquid & $\mathrm{H}$ \\
\hline & SODIUM BICARBONATE & $4.20 \%$ & Injection & $\mathrm{H}$ \\
\hline & SODIUM BICARBONATE & $8.40 \%$ & Injection & $\mathrm{H}$ \\
\hline CONTRAST AGENT & SODIUM CHLORIDE & $10 \%$ & Injection & $\mathrm{H}$ \\
\hline
\end{tabular}

